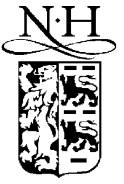

ELSEVIER

\title{
Investigation of surface composition of electrodeposited black chrome coatings by X-ray photoelectron spectroscopy
}

\author{
C. Anandan ${ }^{\mathrm{a}}$, V.K. William Grips ${ }^{\mathrm{a}}$, K.S. Rajam ${ }^{\mathrm{a},{ }^{*}, \text { V. Jayaram }}{ }^{\mathrm{b}}$, Parthasarathi Bera ${ }^{\mathrm{b}}$ \\ ${ }^{a}$ Surface Engineering Unit, National Aerospace Laboratories, Post Bag No. 1779, Bangalore 560017 , India \\ ${ }^{\mathrm{b}}$ Solid State and Structural Chemistry Unit, Indian Institute of Science, Bangalore 560 012, India
}

Received 18 January 2002; accepted 7 March 2002

\begin{abstract}
Solar selective black chromium coating was electrodeposited on pre-treated electroformed nickel substrates from a hexavalent chromium containing bath. The composition of the film was investigated before and after annealing at $400{ }^{\circ} \mathrm{C}$ for different durations. In the as-deposited condition, the surface of the film was found to have trivalent chromium hydroxide and chromium in the chromate form contrary to previous studies which report the presence of hydroxides and metallic chromium. However in the present study, no evidence for metallic chromium was found. The major component, chromium hydroxide, was converted to $\mathrm{Cr}_{2} \mathrm{O}_{3}$ on annealing at $400{ }^{\circ} \mathrm{C}$ with the loss of water vapor. The chromate form remains but with a lowered concentration. (C) 2002 Elsevier Science B.V. All rights reserved.
\end{abstract}

Keywords: Solar selective coatings; Black chrome; X-ray photoelectron spectroscopy

\section{Introduction}

Solar selective coatings absorb solar radiation and convert it into thermal energy directly to be used in solar thermal converters. Therefore, the coatings are expected to possess high absorptance for the solar spectrum and a low emittance at thermal wavelengths [1]. Solar selective black chrome coatings are electrodeposited on metallic substrates such as nickel, copper, stainless steel etc. from chromic acid solutions containing special additives. The electrodeposition route has found wide acceptance for large scale and large area commercial applications. Several studies

\footnotetext{
* Corresponding author. Tel.: +91-80-5210113; fax: +91-80-5086247.

E-mail address: rajam@css.cmmacs.ernet.in (K.S. Rajam).
}

have been reported in the past on the nature of the microstructure and chemical composition of black chrome coatings and their influence on the performance and degradation of the coatings as selective absorbers [2-4]. These in turn have been used to optimize the bath composition and deposition conditions. Though all the micro structural models agree that the film is composed of metallic chromium and chromium oxide, they differ in the way both are distributed throughout the film. Starting from a simple model of metallic particles embedded in a dielectric matrix, the models have evolved to a graded composite, one in which the top layer is almost entirely made up of oxide and the substrate/film interface rich in metallic chromium. In general, it has been accepted that the coating is a graded composite of metallic chromium particles and oxide in the bulk, and predominantly oxide on the surface. The size of the 
metallic particles is supposed to vary between 500 and $1000 \AA$ and to increase towards the substrate.

Morphological studies using scanning electron microscopy (SEM) has presented evidence for a micro rough surface with voids in it [5,6]. Further, X-ray diffraction and transmission electron microscopy has shown that the initial amorphous oxide envelope crystallizes on annealing at temperatures $>300{ }^{\circ} \mathrm{C}$ into $\mathrm{Cr}_{2} \mathrm{O}_{3}$ structure and also that micro voids appear [6]. The substrate morphology and structure has been found to play an important role in determining the structure of the black chromium films and its thermal stability [7]. Surface science techniques such as Auger electron spectroscopy (AES), X-ray photoelectron spectroscopy (XPS) and secondary ion mass spectroscopy (SIMS) has been used to study the chemical composition of the coatings $[3,8,9]$. These techniques have shown that in the as-deposited condition the coating is composed of chromium hydroxide, especially the near-surface region is almost entirely made up of it, and metallic chromium. Presence of trapped hydrogen and other impurities, mainly arising from the cathode material and additives to the electrolyte, have also been found in the film $[8,9]$. Thermal annealing at temperatures $\left(<400{ }^{\circ} \mathrm{C}\right)$ converts the hydroxide into oxide with the loss of water molecules and hydrogen. In this process some of the metallic chromium is also oxidized. It may be mentioned here that chromic acid solutions are also used for many other surface treatments of metals such as bright chrome plating, anodizing, passive film formation, chromate conversion coatings for corrosion resistance, etc. and recent studies have shown the presence of hexavalent chromium in some of these coatings along with other forms of chromium.

In the present study, we report our findings on the composition of the near-surface region of the asdeposited and annealed black chrome coatings as determined by XPS. As will be seen, these findings, in addition to confirming some of the earlier observations, also provide new information on the composition of the near-surface region.

\section{Experimental}

The black chromium films were electrodeposited on nickel substrates in a bath with the following composition:

$\begin{array}{ll}\text { Chromium trioxide } & 400 \mathrm{~g} / \mathrm{l} \\ \text { Catalyst A } & 5 \mathrm{~g} / \mathrm{l} \\ \text { Catalyst B } & 10 \mathrm{~g} / 1 \\ \text { Catalyst C } & 0.5 \mathrm{~g} / 1\end{array}$

The substrates were $0.25 \mathrm{~mm}$ thick electroformed nickel, degreased in trichloroethylene and then cathodically cleaned for $1 \mathrm{~min}$ in $10 \% \mathrm{NaOH}$ at $15 \mathrm{~A} / \mathrm{dm}^{2}$ and at ambient temperature. The sheets were then rinsed in tap water and then dipped in $25 \%$ hydrochloric acid. Finally, after rinsing in tap water, the sheets were dipped in $10 \% \mathrm{HNO}_{3}$ and thoroughly rinsed in tap water and distilled water before depositing the black chromium. Black chromium was immediately electrodeposited at a current density of $30 \mathrm{~A} /$ $\mathrm{dm}^{2}$ and at a bath temperature of $20^{\circ} \mathrm{C}$ for $140 \mathrm{~s}$. For annealing experiments, the samples were kept in a petri dish and placed in an air-circulated oven maintained at $400{ }^{\circ} \mathrm{C}$. The samples were studied as asdeposited and after annealing at $400{ }^{\circ} \mathrm{C}$ for 30 and $60 \mathrm{~min}$ and $2 \mathrm{~h}$.

$\mathrm{X}$-ray photoelectron spectra were obtained in a vacuum generator ESCA-III Mk2 system consisting of $\mathrm{Al} / \mathrm{Mg}$ twin anode $\mathrm{X}$-ray source and a hemispherical analyzer. In the present study Al X-ray source with a photon energy of $1486.6 \mathrm{eV}$ was used. The incident X-ray power was $125 \mathrm{~W}$ and is nonmonochromatic. The samples were degreased with methanol prior to loading. Chromium 2p, oxygen 1 s and carbon $1 \mathrm{~s}$ core level spectra with 30 and $50 \mathrm{eV}$ pass energies and valence band spectra in the $0-15 \mathrm{eV}$ range with $50 \mathrm{eV}$ pass energy were obtained. The binding energies reported here are carbon $1 \mathrm{~s}$ $(284.6 \mathrm{eV})$ binding energy referenced and have an accuracy of $\pm 0.1 \mathrm{eV}$. Compositional analysis was carried out using the area under each core level spectrum obtained after subtraction of a linear background. For atomic sensitivity factors the values listed in [10] were used. These are 1.7 for $\mathrm{Cr} 2 \mathrm{p}_{3 / 2}$ and 0.63 for $\mathrm{O} 1 \mathrm{~s}$ core level. The $\mathrm{Cr} 2 \mathrm{p}_{3 / 2}$ core level spectra were analyzed for identifying elemental as well as different charge states by fitting gaussian peaks to the spectra after a linear background subtraction. For the gaussian peaks, a higher full width at half maximum (FWHM) for charge states other than $\mathrm{Cr}^{0}$ (elemental) was used and this was kept constant for all charge states. 


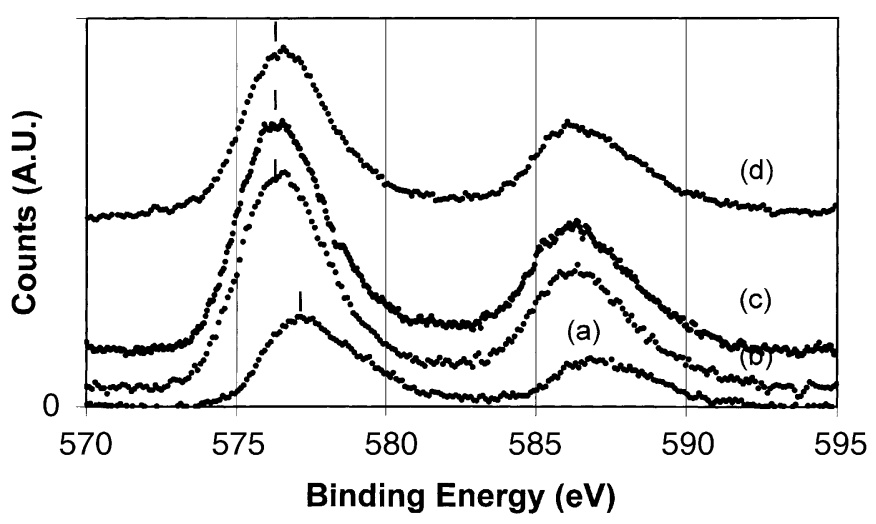

Fig. 1. Chromium $2 p$ core level spectra from the as-deposited and annealed samples. The labels correspond to: (a) as-deposited, (b) $400{ }^{\circ} \mathrm{C} /$ $30 \mathrm{~min}$, (c) $400{ }^{\circ} \mathrm{C} / 60 \mathrm{~min}$, and (d) $400{ }^{\circ} \mathrm{C} / 2 \mathrm{~h}$ annealed samples.

\section{Results and discussion}

Fig. 1 presents the $\mathrm{Cr} 2 \mathrm{p}$ core level spectra for the as-deposited and annealed samples. The vertical dash marks are a guide to follow the movement of the binding energy of the dominant peak in the unresolved spectra. It is evident from the figure that the binding energy of the $\mathrm{Cr} 2 \mathrm{p}_{3 / 2}$ core level is higher in the asdeposited film and it decreases on annealing at $400{ }^{\circ} \mathrm{C}$. The shift in the binding energy suggests a change in the chemical state of $\mathrm{Cr}$ after the $30 \mathrm{~min}$ annealing at $400{ }^{\circ} \mathrm{C}$. For further increase in annealing time, the binding energy remains unaffected as can be seen from the spectra (b), (c) and (d) in the figure.

In Fig. $2 a$ and $b$ the $\mathrm{Cr} 2 \mathrm{p}_{3 / 2}$ core level spectra for the as-deposited and one of the annealed samples are shown fitted with two gaussian peaks. Table 1 lists the binding energy of the two components and their atomic concentration in the as-deposited and annealed films. As noted in Table 1, the binding energy of the major component is initially at $576.9 \mathrm{eV}$ and shifts to $576.3 \mathrm{eV}$ in the annealed samples. The minor component at $579.2 \mathrm{eV}$ also undergoes a shift towards lower value after annealing.
Fig. 3 shows the valence band spectra for the asdeposited and annealed samples. In the valence band spectrum of as-deposited sample the peak due to $\mathrm{Cr} 3 \mathrm{~d}$ level is absent and only the broad feature is seen. However, this atomic-like peak occurs at approximately $2 \mathrm{eV}$ after annealing and the deeper lying broad feature show some structure implying the formation of $\mathrm{Cr}_{2} \mathrm{O}_{3}$ in the film after annealing [11].

Fig. 4 presents the oxygen $1 \mathrm{~s}$ core level for the asdeposited and annealed samples. The peak is broad in the as-deposited case and undergoes a shift towards lower binding energy on annealing. The integrated area under the spectrum can be used in estimating the $\mathrm{O} / \mathrm{Cr}$ ratio. The ratio of the area under the oxygen $1 \mathrm{~s}$ core level and Cr 2 p core level is given in Table 1 for different conditions. The values show that in the asdeposited samples the ratio is high and on annealing it decreases. This suggests that some oxygen bearing species are lost during the annealing process.

As discussed above, chromium exists in two different charge states in the black chrome coatings studied. The binding energy of the major component, $576.9 \mathrm{eV}$, in the as-deposited films is that of $\mathrm{Cr}$ in the hydroxide form, either as $\mathrm{Cr}(\mathrm{OH})_{3}$ or $\mathrm{CrOOH}$ form.

Table 1

Binding energy and atomic $\%$ of different chromium species

\begin{tabular}{|c|c|c|c|c|c|c|c|c|}
\hline \multirow[b]{2}{*}{ Binding energy $(\mathrm{eV})$} & \multicolumn{2}{|c|}{ As-deposited } & \multicolumn{2}{|c|}{$400{ }^{\circ} \mathrm{C} / 30 \mathrm{~min}$} & \multicolumn{2}{|c|}{$400{ }^{\circ} \mathrm{C} / 60 \mathrm{~min}$} & \multicolumn{2}{|c|}{$400{ }^{\circ} \mathrm{C} / 2 \mathrm{~h}$} \\
\hline & 576.9 & 579.2 & 576.3 & 578.4 & 576.2 & 578.4 & 576.4 & 578.4 \\
\hline Atomic $\%$ & 72 & 28 & 78.5 & 21.5 & 77.2 & 22.8 & 79.9 & 20.1 \\
\hline$I(\mathrm{O}) / I(\mathrm{Cr})$ & 1.15 & & 0.64 & & 0.61 & & 0.63 & \\
\hline
\end{tabular}



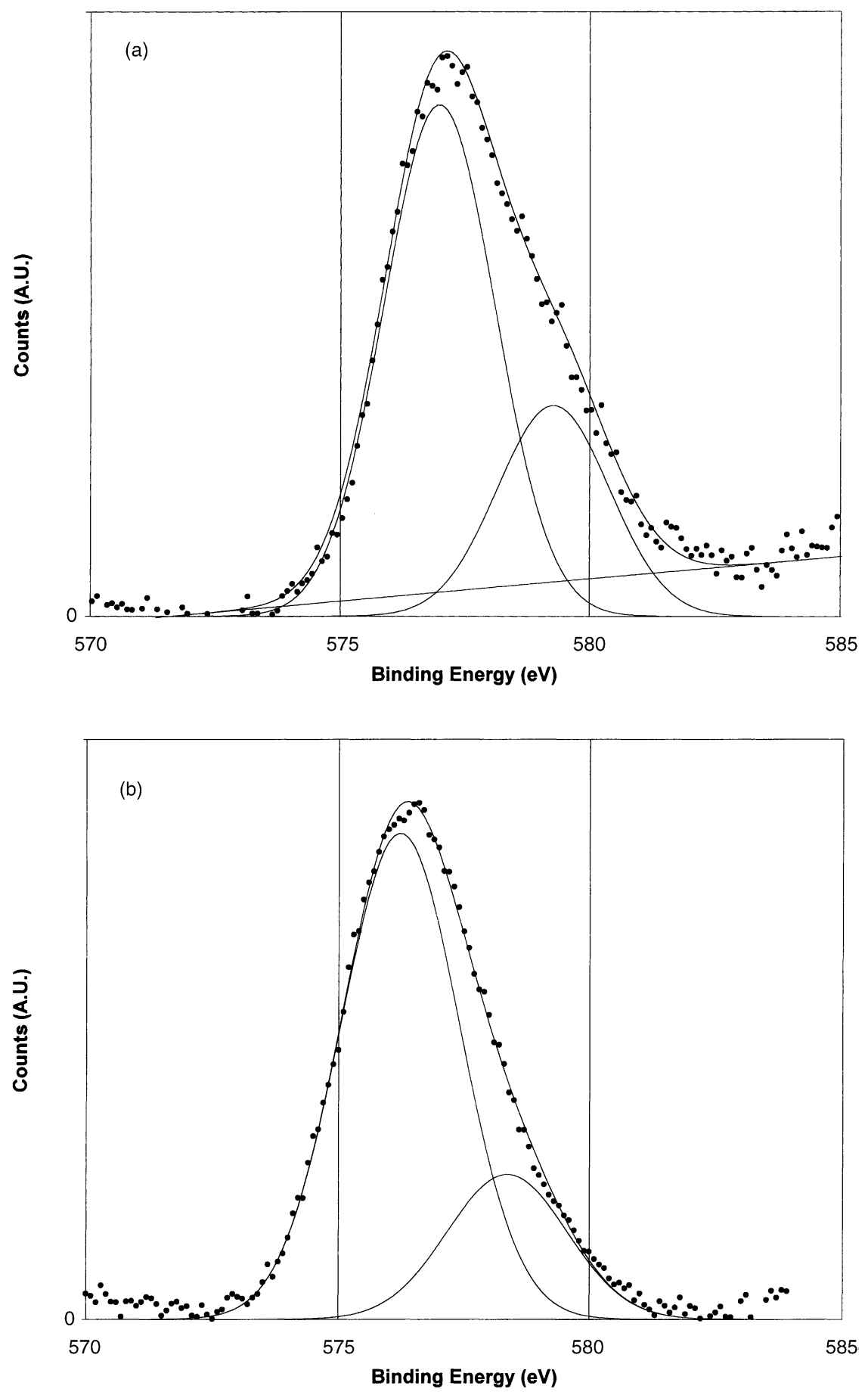

Fig. 2. Chromium $2 \mathrm{p}_{3 / 2}$ core level resolved into different components: (a) as-deposited sample, and (b) annealed sample (400 $\left.{ }^{\circ} \mathrm{C} / 30 \mathrm{~min}\right)$. 


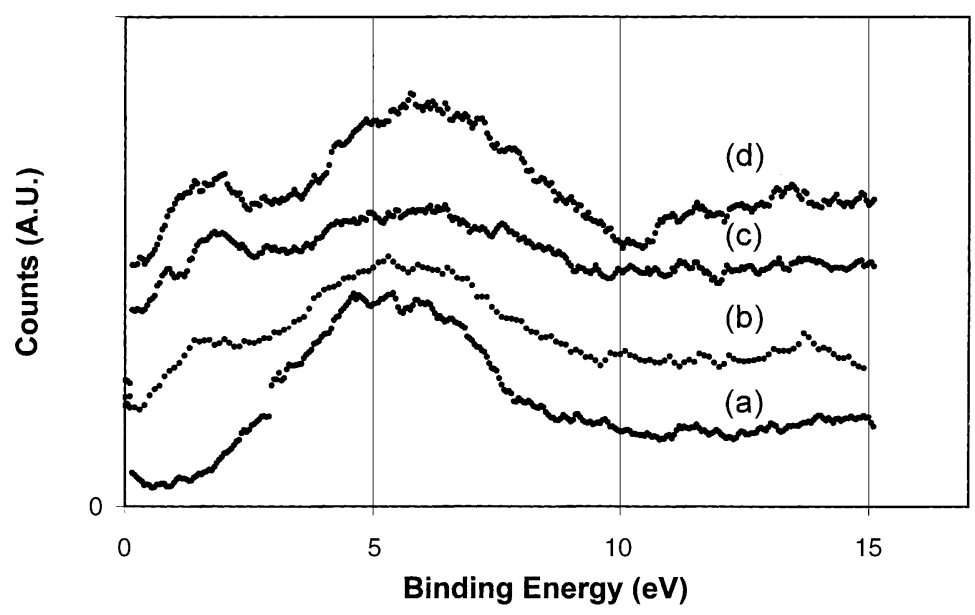

Fig. 3. Valence band spectra in the $0-15 \mathrm{eV}$ range from the as-deposited and annealed samples. The labels correspond to: (a) as-deposited, (b) $400{ }^{\circ} \mathrm{C} / 30 \mathrm{~min}$, (c) $400{ }^{\circ} \mathrm{C} / 60 \mathrm{~min}$, and (d) $400{ }^{\circ} \mathrm{C} / 2 \mathrm{~h}$ annealed samples.

The binding energy of the other component, i.e. $579.2 \mathrm{eV}$, is that of the $\mathrm{Cr}$ in the chromate form and hence indicates the presence of chromate in the film [10]. The exact nature of the chromate, i.e. dichromate or trichromate or in some polymeric form, is not clear. A binding energy of $576.3 \mathrm{eV}$ for the $\mathrm{Cr} 2 \mathrm{p}_{3 / 2}$ core level in the annealed samples corresponds to that of $\mathrm{Cr}$ in the oxide $\mathrm{Cr}_{2} \mathrm{O}_{3}$. Therefore, as reported in earlier studies, annealing the samples converts the hydroxides into oxides. The binding energy of the chromate component also shifts slightly to lower values. Changes in the valence band spectra in Fig. 3 and oxygen 1s core level spectra in Fig. 4 also confirm that a change in the chemical state of $\mathrm{Cr}$ in the film takes place on annealing at $400{ }^{\circ} \mathrm{C}$. The change in chemical state of $\mathrm{Cr}$ from hydroxide to oxide leads to loss of oxygen and hydrogen in the form of water molecules and hydrogen. This is supported by the decrease in the $\mathrm{O} / \mathrm{Cr}$ ratio after annealing. Also, independent thermogravimetric analysis (TGA) measurements (not

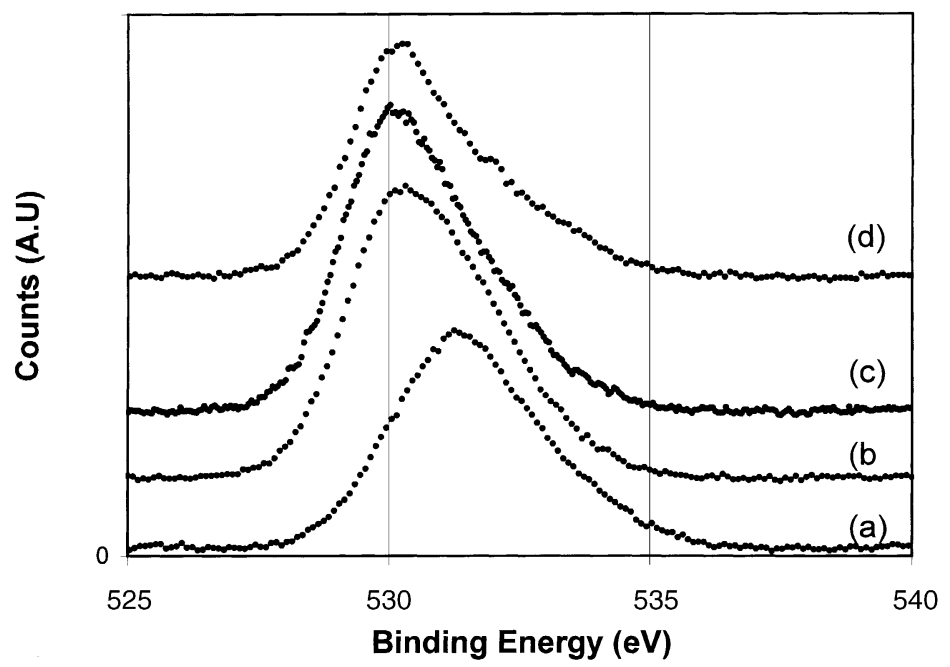

Fig. 4. Oxygen $1 \mathrm{~s}$ core level spectra from the as-deposited and annealed samples. The labels correspond to: (a) as-deposited, (b) $400{ }^{\circ} \mathrm{C} /$ $30 \mathrm{~min}$, (c) $400{ }^{\circ} \mathrm{C} / 60 \mathrm{~min}$, and (d) $400{ }^{\circ} \mathrm{C} / 2 \mathrm{~h}$ annealed samples. 
presented here) have shown that the film undergoes a weight loss after annealing.

The results presented above indicate that chromium is present in more than one chemical state in electrodeposited black chromium films. Earlier studies also identified two components: the hydroxide and metallic components in the as-deposited films, and the oxide and metallic components in the annealed ones. The near-surface region of the as-deposited films was found to be rich in chromium hydroxide and the substrate/film interface was found to be rich in metallic particles. Annealing at temperatures $<400{ }^{\circ} \mathrm{C}$ converts the hydroxide into $\mathrm{Cr}_{2} \mathrm{O}_{3}$ with the release of water molecules. For temperatures $>400{ }^{\circ} \mathrm{C}$ and for long hours of annealing, a significant part of the metallic component was also oxidized resulting in the degradation of the film's performance as a solar selective coating. In the present study also, the nearsurface region of the as-deposited black chromium film was found to be rich in chromium hydroxide. However in addition to this, the presence of chromate form of chromium has also been identified. Annealing has, as in previous studies, resulted in the formation of $\mathrm{Cr}_{2} \mathrm{O}_{3}$ from the hydroxide with the release of water molecules. The chromate concentration has also decreased slightly suggesting that it may have also participated in the reaction sequence that converts the hydroxide into $\mathrm{Cr}_{2} \mathrm{O}_{3}$ in the film as it happens in the deposition process.

Although no reports on the presence of $\mathrm{Cr}^{6+}$ in black chrome coatings is available to our knowledge, its presence in the passive films formed on stainless steels in deaerated acid solutions is well known. XPS studies of these films have shown the presence of $\mathrm{CrO}_{4}{ }^{2-}$ and $\mathrm{CrO}_{3}[12,13]$. Similarly, in situ XANES study of passive films on sputter-deposited stainless steel has confirmed the above findings regarding the presence of chromate [14]. Balasubramanian and Melendres have recently presented evidence in the form of XANES spectra for the presence of hexavalent chromium in the oxide films deposited cathodically onto graphite substrates from a bath containing $\mathrm{Cr}^{6+}$ solution [15]. In fact, hexavalent chromium is also present along with the expected trivalent chromium in these films. Further, XANES, XPS and Raman studies of chromate conversion coatings on aluminum and its alloys for corrosion protection also show the presence of hexavalent chromium [16-19]. Therefore, the presence of chromate form of chromium in black chrome coatings, as found in the present study, is to be expected.

The presence of hydroxide in as-deposited black chromium coating and its conversion to oxide on annealing is, as discussed above, in conformity with earlier studies of similar kind. It is known that the deposition of chromium by the reduction of hexavalent chromium in the bath takes place through intermediate steps involving the formation of various chromates [20]. Further, metallic substrates when immersed in aqueous chromic acid solutions are coated with a strongly adherent cathodic layer of negligible conductivity even in the absence of an electric current through the system. This cathodic layer is made of complex chromates, hydroxides, oxides, water and impurities and ions of the cathode material [21]. This passivating film may persist or dissolve during black chromium deposition depending on the extent of cathodic polarization, the concentration of different catalysts and additives. It also depends on the orientation of the crystal plane at the surface of the substrate and defects such as grain boundaries and dislocations present at the surface. Black chromium deposition takes place by the formation and penetration of the reduction products through this protective layer at sites that are depassivated selectively and at places that are thin enough. On reaching the interface, the reduction products, some of them like metallic chromium, get deposited at the interface. As the deposition proceeds, the metallic particles grow in size and the remaining cathodic film and other reduction products surround the growing metallic particles. Thus the metallic particles are covered by the dielectric component of the black chrome film. Since the growth of the film occurs at the substrate/film interface rather than at the electrolyte/film interface, the cathodic film is pushed towards the surface of the deposited film. Further as the deposition proceeds, the cathodic film is formed and dissolved selectively at the electrolyte/ film interface. Thus, incorporation of some of the cathodic film into the growing black chromium film may also take place. When the deposition process is terminated, the undissolved cathode film is expected to be present on the film. As some of the chromate components present in the film may participate in the annealing-induced reactions with the hydroxides to 
form $\mathrm{Cr}_{2} \mathrm{O}_{3}$, its concentration may be expected to decrease as observed here.

\section{Conclusion}

The surface composition of the electrodeposited black chrome films has been characterized by XPS in the as-deposited condition and after annealing at $400{ }^{\circ} \mathrm{C}$ for different durations. In the as-deposited condition, the surface of the film is rich in trivalent chromium hydroxides. In addition to this we report the presence of chromate form of chromium in the film. No evidence for the presence of metallic chromium on the surface was found. Thermal annealing at $400{ }^{\circ} \mathrm{C}$ leads to the conversion of the hydroxide into $\mathrm{Cr}_{2} \mathrm{O}_{3}$. The hexavalent chromate remains even after annealing. This thermal treatment has been found to stabilize the coating which can be beneficially used for improvement in the solar selective properties of the coatings.

\section{Acknowledgements}

The authors would like to thank the Director, NAL for permission to publish the work, and Dr. (Mrs.) Indira Rajagopal and Dr. S.R. Rajagopalan for their support and encouragement during the course of the work. The authors also wish to thank Prof. M.S. Hegde, SSCU, I.I.Sc., Bangalore, for his encouragement in the XPS work. Authors (V.J. and P.B.) would like to thank Department of Science and Technology (DST), Govt. of India for financial support.

\section{References}

[1] S.W. Hogg, G.B. Smith, J. Phys. D 10 (1977) 1863.

[2] P.M. Driver, R.W. Jones, C.K. Riddiford, R.J. Simpson, Solar Energy Mater. 19 (1977) 301.

[3] C.M. Lambert, SPIE 161 (1978) 84.

[4] G. Zajac, G.B. Smith, A. Ignatiev, J. Appl. Phys. 51 (1980) 5544.

[5] C.M. Lambert, Thin Solid Films 72 (1980) 73.

[6] A. Ignatiev, P. O’Neill, G. Zajac, Solar Energy Mater. 1 (1979) 69.

[7] G.B. Smith, K. Teytz, P. Hillery, Solar Energy Mater. 9 (1983) 21.

[8] G.B. Smith, G. Zajac, A. Ignatiev, Surf. Sci. 114 (1981) 614.

[9] D.M. Fell, L.L. Tongson, S.V. Krishnaswamy, R. Messier, I.S.I. Tsong, J. Vac. Sci. Technol. 17 (1980) 358.

[10] J.F. Moulder, W.F. Stickle, P.E. Sobol, K.D. Bomben, Handbook of X-ray Photoelectron Spectroscopy, Physical Electronics Eden Prairi, MN, 1995.

[11] K. Asami, K. Hasimoto, Corros. Sci. 17 (1977) 559.

[12] A.R. Brooks, C.R. Clayton, K. Doss, Y.C. Lu, J. Electrochem. Soc. 133 (1986) 2459.

[13] C.R. Clayton, Y.C. Lu, J. Electrochem. Soc. 133 (1986) 2465.

[14] J.A. Bardwell, G.I. Sproule, B. MacDougall, M.J. Graham, A.J. Davenport, H.S. Isaacs, J. Electrochem. Soc. 139 (1992) 371.

[15] M. Balasubramanian, C.A. Melendres, Electrochem. Acta 44 (1999) 2941.

[16] M. Kendig, S. Jeanjaquet, R. Addison, J. Waldrop, Surf. Coat. Technol. 140 (2001) 58.

[17] Z. Yu, H. Ni, G. Zhang, Y. Wang, S. Dong, G. Zhao, Appl. Surf. Sci. 62 (1992) 217.

[18] K. Asami, M. Oki, G.E. Thomson, G.C. Wood, V. Ashworth, Electrochem. Acta 32 (1987) 337.

[19] J. Zhao, G. Frankel, R.L. McCreery, J. Electrochem. Soc. 145 (1998) 2258.

[20] J.P. Hoare, J. Electrochem. Soc. 126 (1979) 190.

[21] P.M. Driver, Solar Energy Mater. 4 (1981) 179. 